\title{
SUSTENTABILIDADE DO AGRONEGÓCIO: UM PANORAMA SOCIOLÓGICO
}

Jorge Gama da Silva Junior ${ }^{1}$, Caroline Kraus Luvizotto ${ }^{2}$

${ }^{1}$ Aluno do curso de graduação em Ciências Contábeis da UNOESTE, bolsista PIBIC/CNPq. ${ }^{2}$ Docente do Mestrado em Meio Ambiente e Desenvolvimento Regional e do Mestrado em Educação da UNOESTE. Email: jorgegamajr@hotmail.com. Pesquisa financiada pelo CNPq - Conselho Nacional de Desenvolvimento Científico e Tecnológico

\section{RESUMO}

O agronegócio é entendido como a cadeia produtiva que envolve desde a fabricação de insumos, a produção nas unidades agropecuárias, a sua transformação até o seu consumo. Ao se tratar de agronegócio faz-se necessária a compreensão de processos inter-relacionados que vão além do crescimento agrícola e do aumento da produtividade, referências mais comuns nos debates sobre o setor. Isso significa dizer que deve ser considerado o conjunto de situações e relações sociais que não estariam aí compreendidas. Nesta perspectiva, o agronegócio tornou-se um dos temas de estudo mais atuais da Sociologia Rural. O objetivo geral deste estudo foi apresentar um panorama do agronegócio em perspectiva sociológica. Especificamente, foram demonstradas a(as) sociedade(s) envolvida(s) no agronegócio e os fatores representativos para a sustentabilidade da atividade. Trata-se de um estudo exploratório, descritivo, de abordagem qualitativa, ancorado na análise da literatura relacionada ao tema.

Palavras-chaves: Agronegócio; Sustentabilidade; Sociedade; Desenvolvimento econômico; Sociologia Rural.

\section{INTRODUÇÃO}

O cenário nacional e internacional evidencia constantes e profundas modificações no ambiente dos negócios. São mudanças que surgem de forma rápida e provocam um aumento considerável dos riscos associados aos empreendimentos de qualquer natureza. Entre essas mudanças a globalização da economia, a regulamentação e desregulamentação dos mercados, a crise e a estabilização econômica em diversos países e a intensa evolução tecnológica se sobressai e atinge desde os pequenos empreendimentos até os grandes conglomerados empresariais (BECK, 1997).

De acordo com Elias (2006), o agronegócio também é afetado de forma muito direta. Para um agricultor ou criador manter a sua atividade é preciso se adaptar à nova realidade, buscar inovações tecnológicas e práticas administrativas modernas que levem em consideração tanto os recursos humanos, quanto a conservação ambiental e elementos contábeis, por exemplo.

Ao se tratar de agronegócio faz-se necessária a compreensão de processos interrelacionados que vão além do crescimento agrícola e do aumento da produtividade, referências mais comuns nos debates sobre o setor. Isso significa dizer que deve ser considerado o conjunto 
de situações e relações sociais que não estariam aí compreendidas, uma vez que têm sido apontadas como obstáculo, atraso ou, ainda, como experiências obsoletas num meio rural cada vez mais industrializado (ELIAS, 2006).

Nesta perspectiva, as Ciências Sociais, em especial a Sociologia como uma das ciências humanas que estuda as unidades que formam a sociedade, ou seja, o comportamento humano em função do meio e os processos que interligam os indivíduos em associações, grupos e instituições, os fenômenos sociais, explicando-os e analisando os homens em suas relações de interdependência, apresenta-se como uma Ciência que pode contribuir para o estudo e compreensão do agronegócio e das situações e relações sociais advindas de sua manutenção.

O agronegócio é um dos temas de estudo mais atuais da Sociologia Rural. Sociologicamente, deve-se compreender o rural para além de um espaço que privilegia a agricultura e a pecuária. O rural é compreendido cada vez mais como um espaço de múltiplas atividades (SCHNEIDER, 1999).

Agricultura e pecuária vem passando nas ultimas décadas por um processo de industrialização e de serviços em geral. Diante disso, a terra deixa de ser o único recurso produtivo à medida que a produção é realizada em ambientes construídos, como a produção de legumes e verduras em estufas, as granjas produtoras de aves, as fábrica-fazendas produtoras de leite (SILVA, 1996). O rural é analisado na perspectiva da reorganização das atividades econômicas, sendo um ambiente reconstruído na perspectiva de uma sociedade industrializada, com inúmeros processos de reorganização social.

As atividades econômicas, tecnológicas, políticas e sociais, ligadas à produção, à transformação, à distribuição e ao consumo de produtos de origem vegetal e animal, têm merecido, ao longo do tempo, atenção destacada das comunidades acadêmicas, governamental e empresarial. Por essa razão, apresentar um panorama geral do agronegócio sob a luz da Sociologia e apontar as relações humanas no agronegócio pode ser importante para compreender os mecanismos de geração de valor e de distribuições desse valor entre os agentes que o produzem.

Neste contexto, o objetivo geral deste estudo é apresentar um panorama do agronegócio na perspectiva sociológica. Especificamente, são demonstradas a(as) sociedade(s) envolvida(s) no agronegócio e os fatores representativos para a sustentabilidade da atividade.

O estudo foi desenvolvido por meio da abordagem qualitativa e configura-se como uma pesquisa de caráter exploratório e descritivo, baseado na interpretação, análise e discussão da literatura relativa ao tema. 


\section{O AGRONEGÓCIO: CONSIDERAÇÕES GERAIS}

O surgimento do agronegócio brasileiro é atribuído historicamente à expansão das fronteiras agrícolas e uso dos recursos naturais, uma forma especial de mineração do solo e recursos naturais (HOLANDA, 1936).

O avanço da modernização agrícola no país apresenta a constituição de um modelo que se espalhou de São Paulo e Paraná para outras regiões do país, sobretudo o Centro-Oeste. Nestas regiões, produtores de carne, leite, soja, milho, algodão, feijão e cana-de-açúcar, por exemplo, estão de alguma maneira relacionados às agroindústrias e com elas negociam produção, crédito e assistência técnica, consolidando assim o agronegócio brasileiro (MARTINE; GARCIA, 1987).

O desenvolvimento do agronegócio se deu de modo mais expressivo no período de 1965 a 1980 com a modernização da agricultura e pecuária brasileira. De acordo com Palmeira e Leite (1998) sua consolidação como atividade econômica se deu a partir dos seguintes aspectos:

(a) A adoção do padrão tecnológico moderno, calcado basicamente no binômio químico mineral-mecanização;

(b) O aumento da produção e da produtividade, ainda que a estrutura fundiária permanecesse inalterada no período, chegando mesmo a atestar uma ligeira concentração da posse da terra;

(c) A importância assumida pelo crédito rural, privilegiando grandes produtores localizados na região Centro-Sul e produtos exportáveis;

(d) A consolidação das cadeias e dos complexos agroindustriais, imprimindo uma dinâmica à produção agropecuária que implicou na sofisticação e diferenciação do produto processado;

(e) A ingerência da esfera financeira nas atividades produtivas do agro, promovendo a integração de capitais agroindustriais e agrocomerciais, bem como fortalecendo a valorização especulativa do imóvel rural e a transformação de ativos reais, como terra e gado, em ativos financeiros;

(f) O crescimento da participação da agricultura brasileira no mercado externo, fundamentado numa política cambial baseada em desvalorizações, atestando, para algumas cadeias específicas, um significativo aumento da exportação de seus principais produtos; 
(g) O aumento da produtividade do trabalho da população empregada no campo e a transformação na própria estrutura das suas relações de trabalho, além de uma intensa migração rural-urbana.

Davis e Goldberg desenvolveram em 1957 o conceito de agrobusiness, visando "contribuir para o estudo das atividades ligadas aos sistemas produtivos de base agropecuária, por intermédio da introdução de conceitos que podem ser considerados originais na teoria dos sistemas" (BATALHA, 2005, p. 10). O agronegócio pode ser compreendido como "a soma das operações de produção e distribuição de suprimentos agrícolas, das operações de produção nas unidades agrícolas, do armazenamento, processamento e distribuição dos produtos agrícolas e itens produzidos a partir deles" (DAVIS; GOLDBERG, 1957).

Numa visão mais ampla, segundo Neves $(2006,14)$, o conceito de agronegócio vem explicar a nova gestão agropecuária em uma unidade produtiva. São um agregado de contratos e agentes articulados, com insumos, revendas, prestadores de serviços, técnicos, comercializadores, entre outros. "A fazenda fica cada vez mais enxuta, eficiente e empresarial. Mudam o perfil e a imagem do fazendeiro, para muito melhor para um moderno empresário".

\section{O AGRONEGÓCIO EM PERSPECTIVA SOCIOLÓGICA}

Drucker (1992) chama a atenção para um processo muito comum nas últimas décadas: a busca por índices de produtividade cada vez maiores baseados no uso intensivo de máquinas e equipamentos, insumos agroquímicos, combustíveis fósseis e na degradação dos recursos naturais, que vem apontando para os limites da sustentabilidade, econômica e ambiental, dos atuais sistemas de produção agrícola. Isso indica que há a necessidade de criação de novos paradigmas para a agricultura e pecuária do século XXI, com evidente necessidade de uso e difusão de novas práticas coerentes com os preceitos do desenvolvimento sustentável.

$\mathrm{Na}$ análise sociológica, o agronegócio afeta diretamente relações sociais, econômicas e ambientais e o fator sustentabilidade é alterado na medida em que surgem conflitos de ordem social, econômica e ambiental. Braga et. al. (2004) consideram um município mais ou menos sustentável quando este é capaz de manter ou melhorar a saúde de seu sistema ambiental, diminuir a degradação, reduzir a desigualdade social e prover os habitantes de condições básicas de vida, bem como de um ambiente construído saudável e seguro, e ainda de construir pactos 
políticos que permitam enfrentar desafios presentes e futuros. Neste contexto também insere-se o agronegócio.

À concepção de agronegócio está ligada a concepção de desenvolvimento econômico. Porém, segundo Mendonça e Mesquita (2007) este discurso está ligado a uma nova compreensão de um modelo latifundiário de concentração de terras. O agronegócio, no Brasil, está interligado, portanto, com as questões recíprocas com atrasos econômicos e políticos, impactos ambientais, coronelismo, clientelismo e de exploração de mão-de-obra. Para compreender essas questões e analisar o agronegócio como um fenômeno social, inserido em uma sociedade complexa e produto da ação social de sujeitos sociais, faz-se uso da Sociologia.

A Sociologia utiliza a análise realizada por diversas ciências sociais que analisam os fenômenos rurais para que possa fazer a sua síntese integradora que assegure a explicação unitária e global da sociedade rural (LAKATOS; MARCONI, 1999). O contexto que analisa o agronegócio leva em conta as ações desenvolvidas pelos homens do campo que conduzem às transformações da agricultura e pecuária. Uma vez o homem do campo transformado em agricultor ou pecuarista, torna-se membro de um grupo reconhecido pela sociedade e um membro ativo da sociedade global, o que exige novas e constantes transformações para atender a demanda dos demais grupos sociais que a completam e que implicam na adoção de um modo de vida totalmente diferente.

\section{SUSTENTABILIDADE DO AGRONEGÓCIO}

O crescimento e expansão do agronegócio pode levar ao alcance das fronteiras Agrícolas, que são as áreas ainda não exploradas. Apesar do grande desgaste que isso pode levar, recebendo os devidos cuidados técnicos e tecnológicos, essas terras podem se tornar adequadamente produtivas. Sobre esse tipo de território, Christoffoli explica:

A dinâmica das regiões de desbravamento dos cerrados e Amazônia se caracterizam como de fronteira. Tanto o espaço geográfico como socioeconômico ainda não se encontram plenamente estruturados e apropriados pela sociedade e pela economia brasileiras. (CHRISTOFFOLI, 2006, p.2)

Isso deve ser pensado em termos de estruturas básicas para que possa haver o continuo desenvolvimento, como um sistema de comunicação adequado, transportes, sejam eles ferroviários, hídricos, estradas, até aeroportos, que possibilitam o deslocamento e comercialização 
dos produtos ali produzidos, ou até o abastecimento de insumos para o cultivos das culturas, além de faltar estruturas de armazenamentos e de energia, seja ela ,elétrica ou combustíveis.

Essas expansões pelas áreas consideradas fronteiras agrícolas, pode gerar desastres ambientes significantes para fauna e flora brasileiras, sendo ameaças até para o fim do cerrado, que seria uma dos mais importantes tipos de biomas pertencentes ao país, sendo assim um importante tesouro biológico nacional.

Isso reflete com clareza nas consequências da evolução nos últimos anos feita pelo agronegócio, e o cerrado não é o único afetado com essa expansão, outro bioma afetado é a Floresta Amazônica. Essa área tem sofrido com desmatamento, diminuindo assim seu sistema biológico, atrapalhando a sobrevivência de diversas espécies de seres vivos, sejam elas animas ou plantas.

O agronegócio provoca consequências desastrosas ao meio-ambiente. Carrega na sua esteira o mais surpreendente e rápido desmatamento de que se tem conhecimento na história brasileira. Este desmatamento atinge dois biomas em especial, o Cerrado e a Floresta Amazônica. (CANUTO, 2004, p.7)

E ainda tem surgimento de vários conflitos de interesses, brigas por terras e algumas vezes ocasionam em expulsão de pequenos agricultores e indígenas para que as grandes indústrias agrícolas possam estabelecer suas atividades de produção em maiores escalas. Assim como diz Christoffoli (2006, p.11) "Desde os anos 60 sua aplicação tem resultado na expulsão de milhões de famílias de pequenos agricultores, trabalhadores rurais e indígenas do campo".

Esse movimento de deslocação de muitas famílias rurais sejam elas de pequenos produtores ou indígenas, onde acabam migrando para as cidades, e sem uma estrutura adequada das cidades para que possa receber esse rebanho de pessoas, acabam por criar moradias desenvolvidas nas áreas urbanas com poucas condições para uma sobrevivência com conforto e estabilidade.

Com isso precisa-se ser revisto alguns fatores preocupantes para não acarretar em mais destruição de bens naturais brasileiros, trazendo uma melhor sustentabilidade no desenvolvimento agrícola, onde o desenvolvimento sustentável como foi apurado por Christoffoli (2006, p.5) , seria um desenvolvimento tecnicamente internacional, que possibilitaria o melhoramento da vida da sociedade atual, não prejudicando suas gerações futuras, sendo assim, teria uma taxa de desenvolvimento constante sem prejudicar o meio ambiente. 


\section{CONCLUSÕES}

No Brasil o agronegócio é caracterizado por grande heterogeneidade entre os vários tipos de unidades de produção, porém, a forma de produção que se destaca no país é a pequena propriedade de base familiar, responsável pela geração de grande parte dos alimentos consumidos diariamente pela população.

Com isso é verificado que o agronegócio é responsável pelo sustento de varias famílias, fornecendo qualidade de vida e meios de sobrevivência, não somente aos grandes portadores de indústrias, mais também aos seus subordinados que fornecem suas técnicas e meios de trabalhos.

Como entendido, o alto índice de produção, foi adquirido através de varias transformação do campo e a principal dela é a grande entrada de máquinas e insumos na área do agronegócio. Essa modernização, foi inicialmente implementada nos estados de São Paulo e Paraná, tendo se espalhado após as demais regiões brasileiras, onde continua se espalhando.

Após identificar quais são os elementos que constituem o agronegócio, as regiões e sociedades envolvidas, os riscos e as principais atividades, concluímos que é de extrema necessidade que para o crescimento sustentável do agronegócio a participação do Estado com a liberação de créditos e projetos que visem a segurança e a qualidade de vida das famílias envolvidas na atividade, bem como, que garantam a preservação ambiental nas regiões onde o agronegócio vem se desenvolvendo com maior intensidade.

\section{REFERÊNCIAS}

BATALHA, M. O. Gestão do agronegócio - textos selecionados. São Carlos: EdUFSCar, 2005.

BECK, U. A Reinvenção da Política: Rumo a uma Teoria da Modernização Reflexiva. IN: BECK, U.; GIDDENS, A.; LASH, S. Modernização Reflexiva. São Paulo: Editora da Universidade Estadual Paulista, 1997.

BRAGA, C.; et al. Índice de sustentabilidade municipal: o desafio de mensurar. Nova Economia. Belo Horizonte, no 14, vol. 3. P. 11-33. setembro-dezembro de 2004.

CANUTO, A. Agronegócio: a modernização conservadora que gera exclusão pela produtividade.

Revista Nera, ano 7, n. 5, ago/set, 2004.

CHRISTOFFOLI, Pedro Ivan. Políticas públicas e expansão recente do agronegócio na fronteira agrícola do Brasil. MPRA, Paper n. 2219, Universidade de Brasília (UNB), 2006. Disponível em http://mpra.ub.uni-muenchen.de/2219/1/MPRA_paper_2219.pdf, Acesso em 20/06/2013.

DAVIS, J. H., GOLDBERG, R. A. A concept of agrobusiness. Division of research graduate school of business administration. Boston: Harvard University, 1957. 
DRUCKER, P.F. The new society of organizations. Harvad Business Review, USA, Sep.-Oct., 1992.

ELIAS, D. Agronegócio e desigualdades socioespaciais. In. ELIAS, D.,PEQUENO, R. Difusão do agronegócio e novas dinâmicas socioespaciais. 1a. ed. Fortaleza: BNB. 2006, p. 25-82.

HOLANDA, S. B. d. Raízes do Brasil. Rio de Janeiro: J. Olympio, 1936.

LAKATOS, E. M. \& MARCONI, M. A. Sociologia Geral. São Paulo: Atlas, 1999.

MARTINE, G.; GARCIA, R. C. Os Impactos sociais da modernização agrícola. São Paulo: Caetés, 1987.

MENDONÇA, M. R.; MESQUITA, H. A. O agro-hidro-negócio no cerrado goiano: a construção das (re)existências. In: I Encuentro Latinoamericano Ciencias Sociales y Represas e II Encontro Brasileiro Ciências Sociais e Barragens. Salvador (BA), 2007. p. 1-15.

NEVES, M. F. Agronegócio do Brasil. São Paulo: Saraiva, 2006.

PALMEIRA, M., LEITE, S. Debates econômicos, processos sociais e lutas políticas. In: Costa, L. F., Santos, R. N. (orgs.) Política e reforma agrária. Rio de Janeiro: Mauad, 1998.

SCHNEIDER, S. Agricultura familiar e industrialização: pluriatividade e descentralização industrial no Rio Grande do Sul. Porto Alegre: Editora da Universidade, 1999.

SILVA, J. G. A nova dinâmica da agricultura brasileira. Campinas: UNICAMP/IE, 1996. 